Farum

Sociológico

\section{Forum Sociológico}

Série II

$36 \mid 2020$

Viver a mobilidade: Percursos, permanências e registos

\title{
Mobilidades temporárias na cidade turística: 0 caso do centro histórico de Lisboa
}

Temporary mobility in the tourist city: The case of the historic center of Lisbon

Luís Vicente Baptista, Jordi Nofre e Maria do Rosário Jorge

\section{(2) OpenEdition}

Journals

Edição electrónica

URL: https://journals.openedition.org/sociologico/9152

DOI: 10.4000/sociologico.9152

ISSN: 2182-7427

Editora

CICS.NOVA - Centro Interdisciplinar de Ciências Sociais da Universidade Nova de Lisboa

Edição impressa

Paginação: 47-55

ISSN: 0872-8380

Refêrencia eletrónica

Luís Vicente Baptista, Jordi Nofre e Maria do Rosário Jorge, «Mobilidades temporárias na cidade turística: O caso do centro histórico de Lisboa», Forum Sociológico [Online], 36 | 2020, posto online no dia 08 outubro 2020, consultado o 31 março 2022. URL: http://journals.openedition.org/sociologico/ 9152 ; DOI: https://doi.org/10.4000/sociologico.9152 


\title{
MOBILIDADES TEMPORÁRIAS NA CIDADE TURÍSTICA: O CASO DO CENTRO HISTÓRICO DE LISBOA ${ }^{1}$
}

\section{TEMPORARY MOBILITY IN THE TOURIST CITY: THE CASE OF THE HISTORIC CENTER OF LISBON}

\section{Luís Vicente Baptista}

Faculdade de Ciências Sociais e Humanas, Universidade Nova de Lisboa (NOVA FCSH) \& Centro Interdisciplinar de Ciências Sociais (CICS.NOVA), Portugal

\section{Jordi Nofre}

Faculdade de Ciências Sociais e Humanas, Universidade Nova de Lisboa (NOVA FCSH) \& Centro Interdisciplinar de Ciências Sociais (CICS.NOVA), Portugal

\section{Maria do Rosário Jorge}

Faculdade de Ciências Sociais e Humanas, Universidade Nova de Lisboa (NOVA FCSH) \& Centro Interdisciplinar de Ciências Sociais (CICS.NOVA), Portugal

\begin{abstract}
Resumo
O surgimento de "novas" mobilidades coloca o homo/mulier mobilis como actor-chave das nossas cidades. Visitantes, turistas, estudantes universitários e migrantes transnacionais mudam e re-significam o(s) quotidiano(s) urbano(s) de múltiplas formas, moldando uma nova topografia social do consumo nesta era móvel digital. Nesse sentido, o turismo, forma por excelência de mobilidade temporária, tem visíveis impactos nos territórios, urbanos e globais. Este artigo visa contribuir, através de um olhar sociológico, para a compreensão das mudanças verificadas em contextos urbanos particulares, destacando o caso do centro de Lisboa através da abordagem das mobilidades nas suas diferentes escalas fenomenológicas (transnacional/urbana/microlocal) e dos seus múltiplos protagonistas, práticas e dinâmicas territoriais.
\end{abstract}

Palavras-chave: turismo, mudanças urbanas, mobilidade, Lisboa

\begin{abstract}
The emergence of "new" mobilities makes homo/mulier mobilis a key player in our cities. Visitors, tourists, university students and transnational migrants change and re-signify urban day-by-day in multiple ways, shaping a new social topography of consumption in this mobile digital age. In this sense, tourism as a form of temporary mobility has visible impacts on territories, urban and global. This article aims to contribute, through a sociological perspective, to the understanding of the changes observed in particular urban contexts, highlighting the case of Lisbon city centre through an approach of mobility, both in its different phenomenological scales (transnational/ /urban/micro-local) and its multiple players, practices and territorial dynamics.
\end{abstract}

Keywords: tourism, urban changes, mobility, Lisbon

\section{Introdução}

Assistimos nas últimas décadas a uma intensificação de movimentos populacionais que percorrem todo o planeta e que tornam menos previsível a sua ocorrência e o sentido em que se produzem.
Ser móvel tornou-se uma marca das sociedades de hoje, só possível graças ao desenvolvimento tecnológico, científico, económico e social que permitiu o acesso generalizado aos transportes colectivos e ao transporte individual. A melhoria das condições de vida de uma parte crescente da população mundial, 
que aconteceu no último século, e o ininterrupto aperfeiçoamento das tecnologias de comunicação e transporte abriram um campo de oportunidades extraordinário à afirmação de identidades móveis.

O homo/mulier mobilis (Amar, 2010) nasce como elemento sine qua non da lógica do capitalismo global povoado por actores emergentes: estudantes internacionais de ensino superior (nomeadamente os estudantes Erasmus); académicos e investigadores em mobilidade internacional; trabalhadores transnacionais (qualificados ou não; formais e informais); refugiados e outros migrantes; reformados transnacionais; turistas, visitantes e viajantes; neonómadas, etc. Estas dinâmicas globais de mobilidade têm um efeito claro na vida dos territórios e das suas populações; afectam de diversas formas as metrópoles, as cidades, os seus subúrbios e os campos. Alguns territórios em particular são mais modificados, é o caso das áreas centrais das muitas cidades do Sul da Europa profundamente alteradas pela expansão do turismo urbano transnacional. A revitalização socioeconómica dos bairros históricos do centro da cidade realizada através da promoção e expansão do turismo tem transformado estes bairros em áreas urbanas voltadas quase exclusivamente para turistas (Sequera \& Nofre, 2018a). Além disso, a turistificação da cidade tem sido frequentemente incentivada pelas autoridades locais através da mobilização de regulamentações específicas de planeamento e ordenamento urbano. O turismo - entendido como uma forma de mobilidade temporária orientada para o lazer - é moldado pelas práticas contemporâneas de consumo, produção e estilo de vida, com visíveis impactos espaciais, sociais, económicos e culturais nos diferentes territórios turistificados.

Embora estas cidades tenham beneficiado com o turismo urbano como motor de reversão dos impactos socioeconómicos da última crise (2008-2014), esta mudança comporta riscos evidentes. Recentemente, um número crescente de autores tem vindo a salientar que a intensa turistificação das suas áreas centrais e a sua ligação a processos de gentrificação transnacional e turística (Barata Salgueiro, Mendes \& Guimarães, 2017; Cócola-Gant, 2018; Füller \& Michel, 2014; Mendes, 2018) se traduz em processos como a expulsão de comunidades locais, o desaparecimento do pequeno comércio tradicional e de equipamentos públicos, e no enfraquecimento de programas sociais locais. Como resultado final, os bairros históricos turistificados tenderão a transformar-se em hotéis-resorts urbanos (Sequera \& Nofre, 2018a).

A cidade turística, ou, se quisermos de outra forma, a parte turística da cidade passa a ocupar um novo lugar não só no contexto da cidade em mudança mas também no circuito turístico global, constituindo mais um ponto no mapa da oferta de destinos a visitar. É com este enquadramento que o presente artigo pretende contribuir para uma abordagem teórica ainda insuficientemente explorada no âmbito da academia portuguesa. Tomando como referência as recentes mudanças socioespaciais na cidade de Lisboa, reflectimos acerca desta forma de mobilidade nas suas diferentes escalas fenomenológicas (transnacional/urbana/microlocal) e dos seus múltiplos protagonistas, com o apoio de breves ilustrações empíricas referentes à turistificação dos bairros históricos do centro da capital portuguesa, nomeadamente o Bairro Alto e Alfama (Figura 1).

\section{Mobilidade e atractividade territorial}

É certo que vivemos actualmente num contexto de economia global em que a circulação dos indivíduos se faz de forma intensa e, tendencialmente, individual e constante. Do ponto de vista social, o valor do indivíduo, o individualismo - ou se quisermos antes o resultado dos processos de individuação, nas palavras de Anthony Giddens (1991) - ganha importância universal e os indivíduos circulam mais facilmente, também do ponto de vista territorial. Estamos perante a generalização de uma lógica que garante o reconhecimento da mobilidade como um direito social.

A mobilidade configura uma liberdade de acção que preenche muitas das aspirações individuais de viver uma vida prazenteira, o que num tempo de valorização do indivíduo intensifica a consciência da finitude de cada um e estimula a predisposição à deslocação. Ser móvel não é apenas ser emigrante, estar condenado a uma mobilidade forçada, é de modo crescente poder viajar por opção, ser turista, ser utilizador dos bens e serviços que por escolha e sem limitação territorial nos são dados a usufruir.

Como observa Hall (2008, p. 8),

o atractivo da "mobilidade temporária" está no cerne da política de turismo (...). Quando as organizações de destino declaram que querem que o seu destino seja competitivo, o que realmente estão a dizer é que querem manter, ou aumentar ainda mais, o número de pessoas móveis temporárias que atraem, aumentando, da mesma forma, a sua despesa média na cidade.

O princípio da atractividade impera como princípio organizador do desejo de viajar. Assim se insere Lisboa nesta dimensão do turismo global. Nesse sentido, interessa salientar aqui alguns dos dados referentes à evolução do turismo na capital portuguesa. Enquanto o número de passageiros de cruzeiros em Lisboa cresceu de 164259 em 2002 para 521042 em 20172, o número total de passageiros transportados no aeroporto de Lisboa 
Figura $1 \triangleright$ Localização do Bairro Alto (1) e do Bairro de Alfama (2)

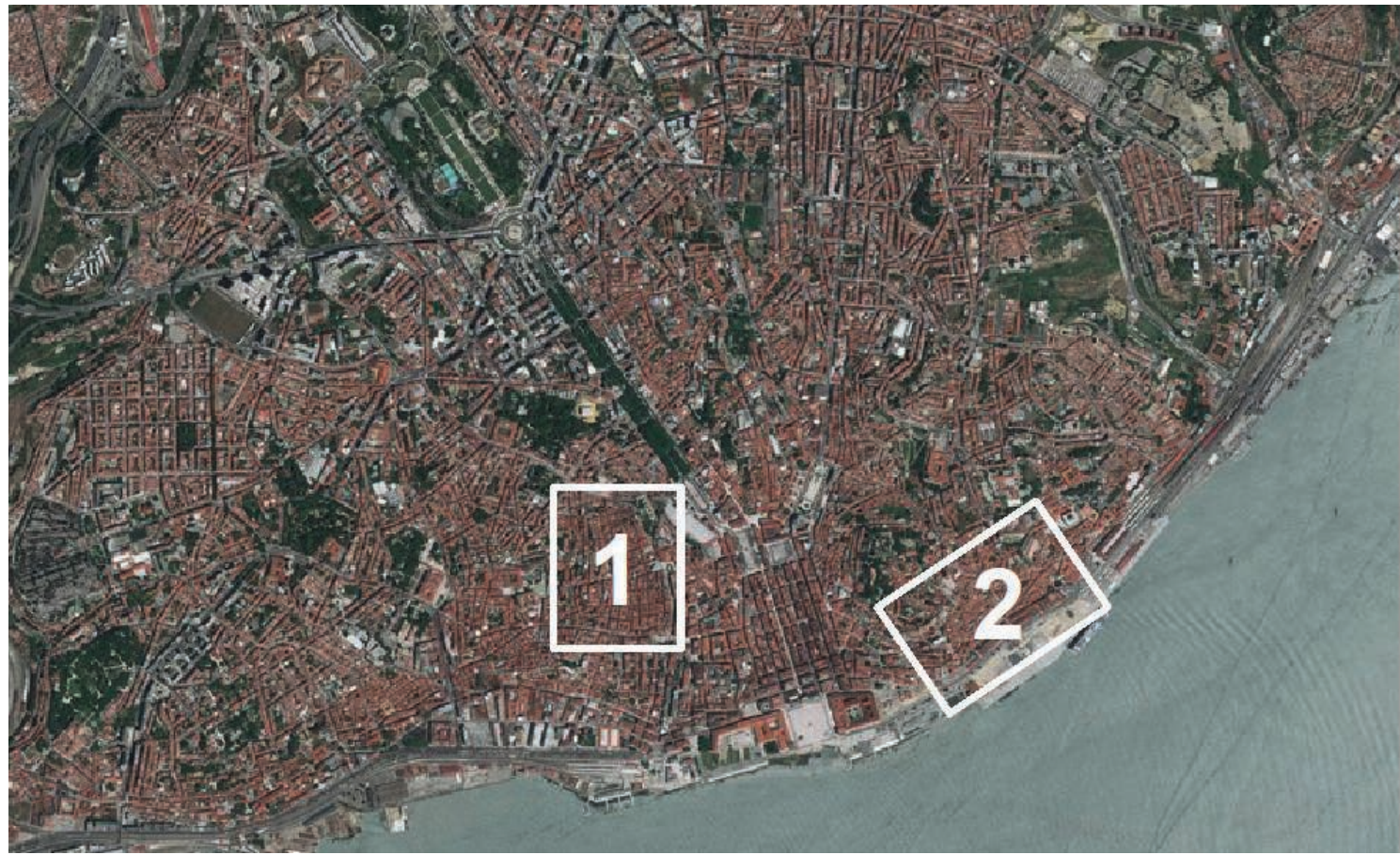

Fonte: Autores, a partir de base cartográfica da ESRI Community Map Contributors CC BY 4.0.

aumentou de 14,8 milhões em 2011 para 29,1 milhões em $2018^{3}$. Acresce que as dormidas nos estabelecimentos hoteleiros da cidade de Lisboa nos últimos anos passaram de 5715176 em 2009 para 12553476 em 2017, enquanto o crescimento do número de hostels a funcionar na cidade - de 97 em 2009 para 229 em 2016 - e de hotéis - de 93 em 2009 para 214 em 2018 - se tem concentrado principalmente no centro da cidade ${ }^{4}$.

\section{Diversidade de capitais de mobilidade e desigualdades sociais no uso do território}

O conceito de mobilidade comporta uma vasta diversidade de situações vividas pelos diferentes viajantes. A mobilidade física dos indivíduos nas sociedades contemporâneas corresponde a uma possibilidade vivida de forma muito diferenciada consoante os capitais acumulados. A chegada e instalação de um residente a um país estrangeiro é indissociável do seu capital económico e social (Bourdieu, 1979). Entre os imigrantes que chegam de batelão à costa do país de destino e o estrangeiro que chega a um outro país na qualidade de director de uma empresa; entre o estudante de doutoramento e o refugiado de uma guerra civil desprovido de meios de sobrevivência estabelece-se uma enorme distância de recursos disponíveis que caracteriza cada uma destas situações que não depende apenas do país de origem de quem chega, mas também do meio social de origem e das redes sociais em que se insere.

A questão da mobilidade espacial, enquanto materialização do processo de mobilidade social, está intimamente ligada à forma como o capital económico e o capital social se transformam em capital de mobilidade (Kaufmann, Bergman \& Joye, 2004). Kaufmann et al. (2004) propõem mesmo uma nova categoria de análise da mobilidade, que designam por "motilidade" (motility), pretendendo alargar o conceito de mobilidade espacial à análise da mobilidade socioespacial. De acordo com esta proposta teórica, a mobilidade social e espacial é concebida como um indicador de formas mais compreensivas de mobilidade que não se limitam às deslocações, mas à capacidade ou ao potencial de mobilidade de entidades (que podem ser indivíduos, grupos, informação ou produtos) no espaço social e geográfico, de acordo com as suas circunstâncias. O conceito de "motilidade" permite incorporar dimensões estruturais e culturais dos movimentos e da acção, para compreender a capacidade real e potencial da mobilidade espacial e social e a forma como esta capacidade varia, e tem diferentes consequências, de acordo com os contextos socioculturais. Este conceito integra "elementos interdependentes relacionados com o acesso a diferentes formas e graus de mobilidade, competência para reconhecer e utilizar as formas de acesso e apropriação de uma escolha em 
particular, incluindo a opção de não agir" (Kaufmann et al., 2004, p. 750).

Situações que ilustram os efeitos da acumulação de capital social e de mobilidade são, por exemplo, o constrangimento sentido por moradores de um certo bairro da cidade que procuram disfarçar o seu endereço exacto quando consideram que a localização da sua residência os desvaloriza socialmente ou a efectiva mudança de local de residência para um endereço mais em conformidade com uma posição social adquirida (Young \& Willmott, 1957) ou a busca de distinção social (Bourdieu, 1979) pretendida por protagonistas de certas viagens turísticas que se sentem valorizados pela possibilidade de se deslocarem a lugares distantes, inacessíveis, distintos.

A consequência da apropriação destes capitais de mobilidade no uso dos territórios é não só a consolidação das distinções sociais já existentes, mas também a sua ampliação. As grandes metrópoles, que dão forma principal à paisagem do século XXI, albergam novas fronteiras, novos guetos, novas zonas de exclusão dos circuitos dominantes que crescem em número e em dimensão. Novas questões, como a segurança e a violência urbana, distinguem as rotas centrais do consumo turístico dos territórios de exclusão. Só uma parte da cidade é recomendável ao turista distraído e, para esse, está planeada a área central, animada na lógica das cidades competitivas que acolhe os residentes móveis e os móveis turistas. As zonas de residência e trabalho, que sustentam esta lógica de cidade competitiva, funcionam como circuitos intercalares, abertos aos que aí trabalham, fazem negócios e habitam, ou seja, aos grupos sociais com acesso ao conforto da modernidade e à mobilidade metropolitana. Fora dos limites da acessibilidade ficam os locais de residência, de trabalho e de permanência nos quais é difícil circular, e que são fáceis de identificar como lugares pouco recomendáveis. A metrópole comporta tudo isto e tudo isto se vive em simultâneo. Mesmo que não entremos no debate acerca das clamorosas distinções entre as sociedades mais capitalizadas e as mais descapitalizadas, é crucial tomar em consideração, independentemente da sociedade a que nos referimos, a existência de distintos capitais de mobilidade que distinguem os seus múltiplos protagonistas.

Em termos globais, os circuitos da mobilidade global têm estimulado o turismo urbano que vem funcionando como fonte de oportunidades para jovens e adultos jovens qualificados (precários), trabalhadores não qualificados e empreendedores (Hall \& Williams, 2008; Proença \& Soukiazis, 2008; Scott, 2006; Thomas \& Augustyn, 2007; Tribe, 2011) ao serviço de uma economia do entretenimento que ganha uma relevância nunca antes atingida (Hannigan, 2010).

\section{Mobilidade temporária e ludificação da cidade}

O processo de ludificação da cidade (Stevens, 2007) e dos territórios em geral (Baptista, 2005) muda a forma como apreendemos os lugares onde vivemos e pelos quais viajamos. O resultado visível designa-se correntemente como turistificação mas está dependente das alterações estruturais das economias e das sociedades contemporâneas. De facto, o aumento do turismo nas nossas cidades, agora globalizado, é o resultado da interacção das diferentes forças sociais, económicas, políticas e tecnológicas que melhoraram a mobilidade numa escala regional, nacional e global. Assim, o estudo do turismo não se refere apenas à indústria do turismo e hotelaria, mas antes se fundamenta no desenvolvimento do consumo e na produção de mobilidade(s) de lazer. Alguns autores vêm considerando o turismo como apenas uma, embora altamente significativa, dimensão da mobilidade temporária (Audrey, 2017; Hall, 2008, 2015; Burns \& Novelli, 2008; Coles \& Hall, 2008; Mavric \& Urry, 2009; Merriman, 2012). Nesse sentido, Merriman (2012) salienta, a partir de uma abordagem pós-estruturalista, a necessidade de repensar a relação entre mobilidade, práticas incorporadas, espaço e lugar no campo dos estudos de turismo. Assim, o autor demonstra como a mobilidade não é simplesmente praticada ou experimentada em relação ao espaço e ao tempo, mas dá origem a diferentes ritmos, forças, atmosferas, afectos e materialidades do consumo cultural e lúdico. Daí que a mobilidade apareça como um conceito explicativo chave nos estudos de turismo.

De facto, em 2008, T. Coles e C. M. Hall publicaram um artigo na Current Issues in Tourism, intitulado "A geografia do turismo está morta. Viva as geografias do turismo e da mobilidade". Coles e Hall argumentaram que "as questões de localização e lugar não podem ser isoladas das relações e ligações entre os espaços e, portanto, das mobilidades do capital, das ideias e das imagens" (Coles \& Hall, 2008, p. 289). Por essa razão, os actuais mecanismos e estratégias de urban branding \& benchmarking encontram-se muito baseados em termos de promoção da mobilidade e atracção de capital (para investimento) e/ou de pessoas - como turistas, trabalhadores ou residentes (com capital económico).

Para além da mobilidade associada ao turismo e ao lazer, a mobilidade refere-se também a um leque de fenómenos socioeconómicos e culturais ligados à emergência de novas gerações de cosmopolitas, de que são exemplo, (i) a experiência de uma estada no estrangeiro no âmbito de cursos do ensino superior e a possibilidade de entrada no mercado de trabalho no futuro 
(Brooks, 2018; Brooks \& Waters, 2011; Cicchelli, 2012; Marinescu, 2017); e (ii) os processos de migração no seio de transições juvenis - incluindo a migração líquida e sua imprevisibilidade intencional (King, 2017).

Estas mobilidades promovidas por políticas de cidade que associam a captação de juventudes qualificadas e criativas ao próprio desenvolvimento competitivo dos seus municípios e regiões estimulam experiências de apropriação e uso de espaços urbanos que se tornam icónicos para as práticas lúdicas destes visitantes.

Em Lisboa podemos referir desde logo a experiência ocorrida no Bairro Alto. Neste bairro histórico do centro de Lisboa, as principais forças motrizes das mudanças urbanas nos últimos cinco anos podem ser interpretadas como resultado de uma interacção simultânea - vivamente promovida no âmbito das políticas públicas urbanas - entre a expansão da economia de lazer nocturno orientada para o turismo e a rápida airbnbização do bairro. Os dados são inequívocos: o alojamento local passou de 525 unidades em Julho de 2015 para 1096 em Agosto de $2019^{5}$, enquanto o número de locais de restauração e de diversão nocturna mais do que duplicaram entre 1997 e 2015 (Nofre et al., 2017). De salientar que, actualmente, a maior concentração de alojamento local se encontra situada na área que conta com a maior densidade de estabelecimentos de lazer nocturno (restaurantes, bares e pequenos clubes) do Bairro Alto (Nofre, 2019) (Figura 2).

\section{Mobilidade e hospitalidade: os desafios do turismo global}

Voltando a uma abordagem mais geral, e situados portanto neste cenário de uma cidade modifi- cada pela permanência de uma população visitante, emerge como tema de reflexão e intervenção pública o conceito de hospitalidade, agora reconfigurado para responder a uma necessidade competitiva de posicionamento dos territórios no mercado do consumo turístico. Aparecem assim associados mobilidade e hospitalidade como duas facetas de um mesmo processo de mudança social que afecta os territórios contemporâneos, correspondendo a políticas nacionais e estratégias transnacionais para a plena circulação dos indivíduos. Este processo, que ocorre hoje com grande intensidade, merece no entanto uma análise mais cuidada.

Em primeiro lugar, é historicamente muito recente $o$ acesso de significativas camadas da população espalhada a nível mundial a um conjunto de meios de deslocação que mudam profundamente o uso dos territórios-alvo do turismo massificado. É uma ideia recente a predisposição generalizada dos indivíduos em variadíssimos contextos culturais para pretenderem deslocar-se a territórios desconhecidos. Em segundo lugar, a turistificação urbana não ocorre do mesmo modo nas diferentes zonas da cidade, o que leva a uma particularização das áreas afectadas pelo facto de serem áreas de consumo turístico e que são, por isso, mais rápida e intensamente renovadas mas também apropriadas pelos visitantes. Contudo, estas dinâmicas produzem necessariamente tensão entre opostos. O termo "hostipitality" (Lynch, Molz, Mcintosh, Lugosi \& Lashley, 2011), que podemos traduzir por hostipitalidade, traduz essa nova realidade: a dualidade de posicionamentos entre hospitalidade e hostilidade, que se faz sentir não só a propósito de quais são os turistas desejáveis e os indesejáveis, nomeadamente a população de viajantes pouco abonados que vagabundeia sobretudo pelas áreas

Figura $2 \triangleright$ Espaços públicos no Bairro Alto com elevada densidade de frequentadores noctívagos (1: Rua Atalaia; 2: Erasmus Corner)
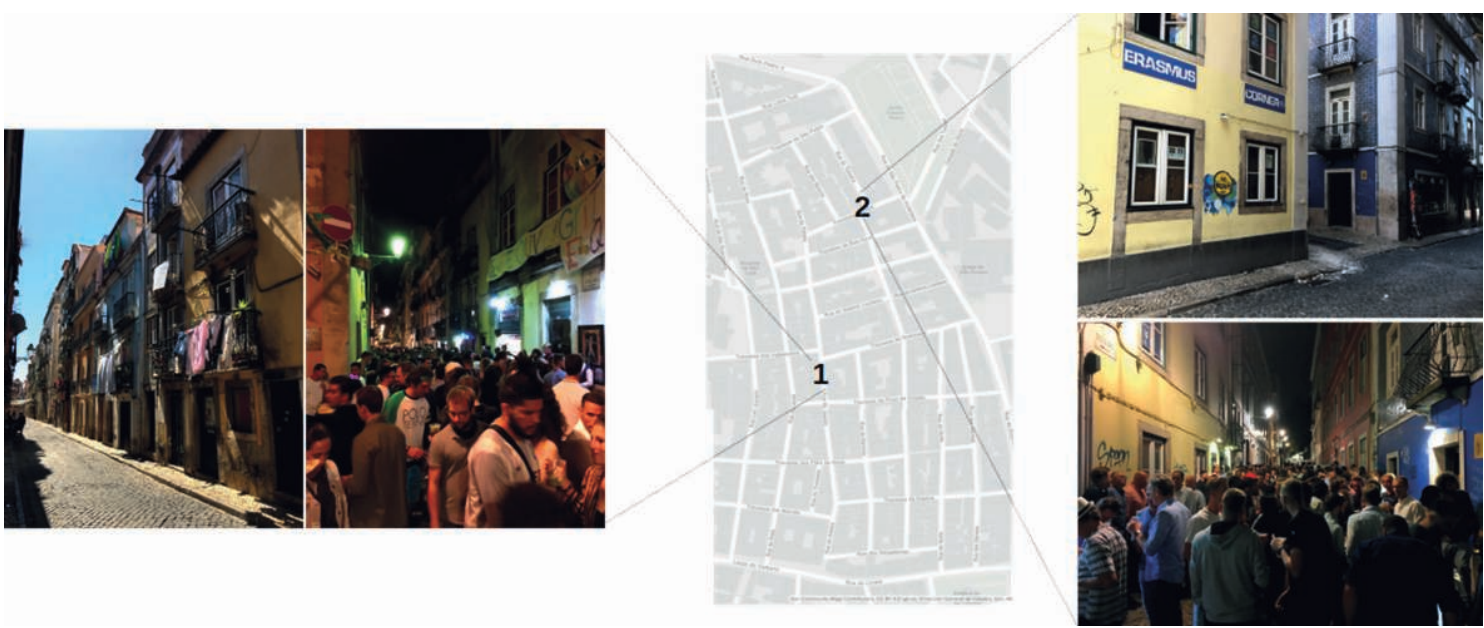

Fonte: Mapa ESRI Community Map Contributors CC BY 4.0.; fotografias J. Nofre, Setembro 2019. 
de consumo turístico mais intenso, mas também na reacção mais genérica de residentes à chegada maciça de visitantes (Colomb \& Novy, 2017).

Em Alfama, onde 48,8\% do alojamento familiar clássico do bairro foi convertido em apartamentos turísticos da Airbnb - em Julho de 2018, era 39,4\% (Sequera \& Nofre, 2019) - , a indignação e raiva dos moradores não se traduz na criação e desenvolvimento de um movimento de moradores contra a turistificação com acções de protesto performativas ou até directas, como acontece, por exemplo, no caso de Barcelona ou Madrid. Em Alfama, a resistência é sinónimo de ressentimento e silêncio, que só é quebrado por alguns poucos moradores nas assembleias da Junta de Freguesia de Santa Maria Maior e em algumas conversas mantidas entre moradores idosos nos (já poucos) cafés e pastelarias tradicionais do bairro, enquanto alguns incipientes grupos de contestação à especulação imobiliária e à turistificação (por exemplo, o Stop Despejos e o Habita) são maioritariamente - e paradoxalmente formados por investigadores sociais que não moram no bairro (Sequera \& Nofre, 2018b) (Figura 3.).

\section{Uma nova ecologia dos bairros turistificados?}

Eu já estava habituada ao bum bum [do bar do $\mathrm{R} / \mathrm{C}$ ] ... mas quando o andar de cima se tornou num Airbnb, era barulho nas escadas, festas da madrugada até o meio-dia, lixo nas escadas...Não quero viver num hostel. (J., licenciada de 36 anos, residente no Bairro Alto e oriunda de uma cidade pequena localizada a norte de Lisboa, Setembro 2015)

Os processos de turistificação de uma área específica não envolvem apenas processos de expulsão de comunidades locais mas também a destruição de "marcos mentais comunitários" e a "perda de pertença ao lugar" entre os moradores "resistentes" (Davidson \& Lees, 2005). Estes impactos são visíveis nomeadamente em muitas cidades do Sul de Europa, como por exemplo em Barcelona, Madrid ou Sevilha (Aramayona \& García-Sánchez, 2019; Jover \& Díaz-Parra, 2019; Nofre, Giordano, Eldridge, Martins \& Sequera, 2018). Na capital andalusa, Jaime Jover e Ibán Díaz-Parra (2019, p. 14) analisam como a turistificação surge como processo disruptivo da gentrificação. Nesse sentido, os autores argumentam que, em Sevilha,

a gentrificação (local e transnacional) e o turismo podem colidir à medida que potencialmente avançam em direcções diferentes. A gentrificação trabalha para transformar bairros para os socialmente privilegiados, enquanto

Figura $3 \triangleright$ Alfama turistificada
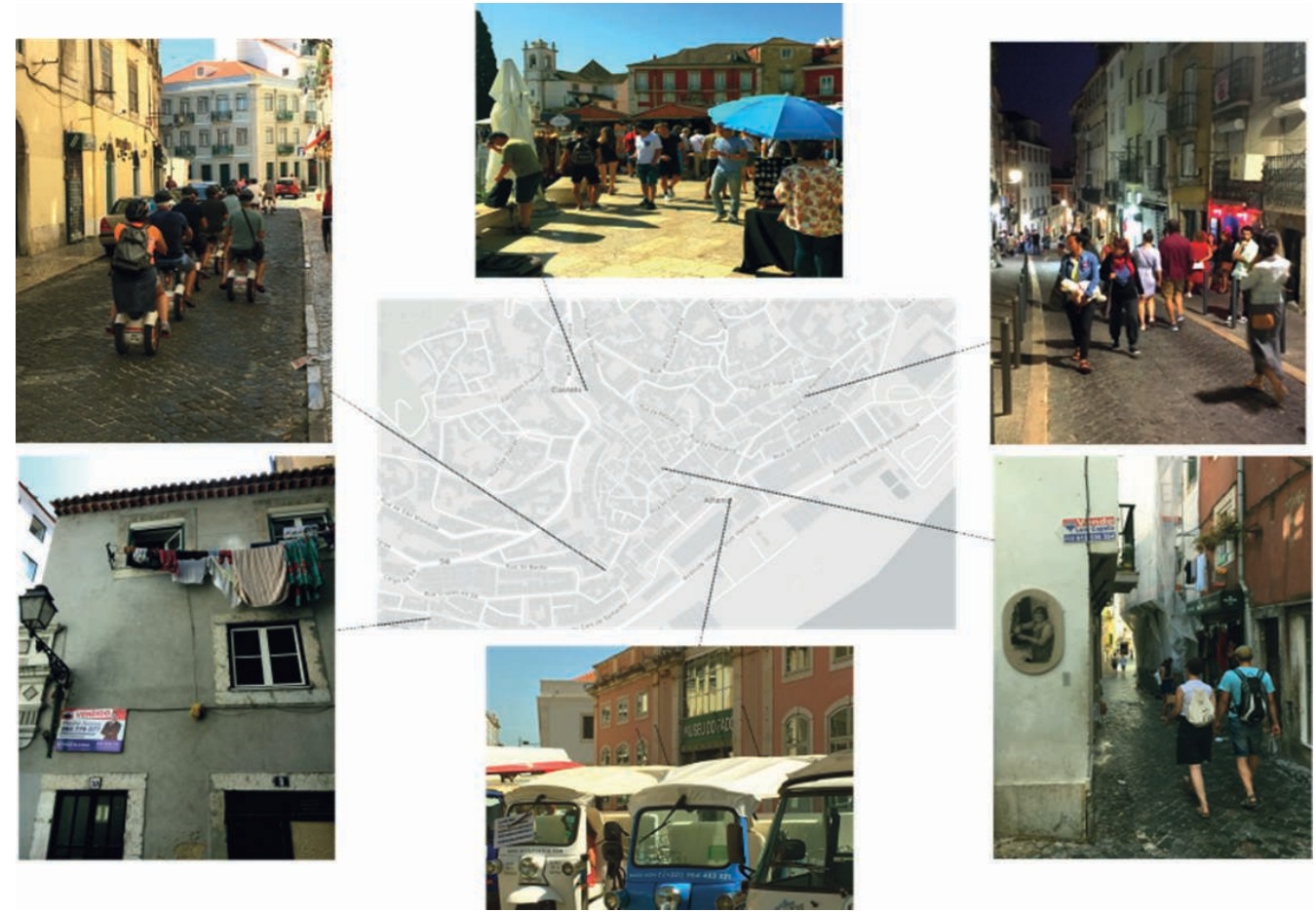

Fonte: Mapa ESRI Community Map Contributors CC BY 4.0; fotografias J. Nofre, Agosto 2019. 
um processo de turistificação visa converter as mesmas áreas em locais exclusivos para turistas (...).

Em Alfama, o processo de turistificação do bairro deu lugar ao surgimento de uma paisagem profundamente disneyficada, na qual o bairrismo (Firmino da Costa, 2008 [1999]) tem sido reconfigurado pelas classes dominantes da cidade através da aplicação de uma "governamentalidade paradoxal". Por um lado, ao longo das últimas duas décadas, o bairrismo tem sido alvo de discursos políticos, mediáticos e legislativos criminalizadores e até pontualmente punitivos com o objectivo de "limpar" social, política e moralmente o bairro para a sua transformação em mercadoria atractiva para o investimento imobiliário especulativo orientado maioritariamente ao alojamento local. Por outro lado, o bairrismo tem sido mercantilizado para a sua transformação em mercadoria de consumo turístico e de experiência autêntica para os seus visitantes. Este processo tem implicado uma profunda reconfiguração (i) das inter-relações espaciais e temporais entre os seus moradores, (ii) das suas diferentes quotidianeidades, e (iii) das (complexas) relações moradores-instituições locais. Em particular, o encerramento de um número importante de bares, tascas e lojas tradicionais de comércio a retalho (talho e charcutaria; legumes e frutas; mercearias) tem significado a perda de espaços-tempos de convívio quotidiano, de relação social e interacção directa entre os moradores e de intercâmbio de informações sobre a comunidade. A sua substituição por lojas de souvenirs low-cost e novos restaurantes e bares orientados exclusivamente para visitantes e turistas configuram uma nova paisagem comercial totalmente desvinculada da comunidade local previamente existente, a qual deixou de formar parte central da vida do bairro e que hoje é instagrameada por visitantes e turistas como mais uma parte do património histórico do bairro. Entretanto, a turistificação do bairro de Alfama tem implicado o surgimento de uma nova topografia social do bairro. Enquanto os "velhos" actores - moradores resistentes ou resilientes, incluindo os gentrificadores da década passada - têm passado a ocupar uma posição político-social marginal, os novos actores locais e transnacionais (investidores, investigadores sociais e comunicação social e digital) reproduzem - sob perspectivas diferentes e até antagónicas - a imagem de uma "nova Alfama" onde os visitantes e os turistas surgem como os novos actores sociais centrais da quotidianeidade do bairro.

\section{Considerações finais}

Com este artigo, a partir de uma leitura centrada nas mobilidades temporárias, apresentamos algumas reflexões em torno das recentes mudanças espaciais, sociais, económicas e culturais dos bairros históricos do centro de Lisboa. Centrados na questão da mobilidade, nas suas diferentes escalas fenomenológicas (transnacional/urbana/micro-local) e nos seus múltiplos protagonistas, práticas e gramáticas territoriais, pretendemos contribuir para o actual debate público e científico sobre a turistificação de Lisboa e os seus impactos junto das comunidades locais. Argumentamos que a mobilidade é hoje um traço ainda mais decisivo para compreender como as cidades estão a mudar, seja por via das migrações de trabalho e dos movimentos pendulares, seja pela importância do turismo.

Mas, como vimos, nem todas as partes da cidade são turísticas. Isto coloca um problema: de que parte da cidade falamos quando falamos de cidade turística? Como se distinguem as zonas ditas residenciais das que incorporam lógicas de exteriorização orientadas para a visita? Em que grau as várias zonas da cidade e da sua área envolvente são afectadas por estas dinâmicas?

O dilema para responder a esta pergunta parece residir no facto de estarmos perante contextos urbanos socioeconómicos e espaciais distintos mas que partilham muitas das imagens que se vão constituindo, produzindo e reproduzindo sobre a cidade turística, neste caso, Lisboa. Nos meios de comunicação imperam as imagens de certas zonas da cidade que são destinos turísticos por excelência, mas que povoam todo o imaginário urbano colectivo, como se toda a vasta área da cidade se pautasse pela mesma lógica. Nestas imagens e nos discursos que lhes estão associados hipervaloriza-se a dimensão lúdica da cidade (Baptista, 2016).

No entanto, com a expulsão de residentes, o envelhecimento da população local "resistente" e o consumo e usufruto maciço e hedonista por parte de milhares de visitantes diários, a condição do alargado centro histórico como zona residencial tende a alterar-se e as dinâmicas vividas localmente vão incorporando a visita como prática quotidiana reconhecida por todos os actores locais - embora, em alguns casos, este reconhecimento seja fruto de uma "derrota" na luta contra a turistificação. Podemos dizer que nas zonas centrais da cidade emergem culturas turistificadas, ou seja, uma mistura entre herança de experiências passadas e uma reanimação da vida local ajustada aos interesses comerciais (e/ou especulativos) de "novos" e "velhos" actores locais (investidores e empreendedores).

Com este olhar em face do fenómeno da turistificação pretendemos contribuir para a análise de como a dimensão da mobilidade global afecta a vida local e torna o espaço local destino lúdico de populações que querem experimentar lugares autênticos. Em termos prospectivos, pretendemos contribuir para uma futura agenda de investigação que vise uma melhor 
e mais aprofundada compreensão dos fenómenos da mobilidade nas sociedades contemporâneas e dos seus impactos sociais, espaciais e económicos em cidades progressivamente turistificadas.

\section{Agradecimentos}

Este trabalho teve o apoio da Fundação para a Ciência e a Tecnologia (CEECIND/01171/2017) e do CICS.NOVA da FCSH, Universidade Nova de Lisboa.

\section{Notas}

1 Por opção dos autores este texto é redigido segundo o Anterior Acordo Ortográfico.

2 Dados sobre o tráfego de passageiros no Porto de Lisboa. Disponível em: http://www.portodelisboa.pt/portal/page/ portal/PORTAL PORTO LISBOA/CRUZEIROS/ESTATISTICAS

3 Número de passageiros no Aeroporto Humberto Delgado, em milhões. Relatório de Gestão de Contas 2018. ANA - Aeroportos de Portugal, Lisboa, 2019. Disponível em: https://www.ana.pt/pt/institucional/publicacoes-e-relatorios/relatorios-de-gestao-e-contas

4 Dados fornecidos pela Associação Turismo de Lisboa; PORDATA - Alojamentos turísticos: total e por tipo de alojamento; e pelo Instituto Nacional de Estatística: Dormidas (N.O) nos estabelecimentos hoteleiros por Localização geográfica (NUTS - 2013) e Tipo (estabelecimento hoteleiro); Série Anual.

5 Dados sobre arrendamento temporário em Lisboa. Disponível em: https://www.airdna.co/vacation-rental-data/ app/pt/lisboa/lisbon/overview

\section{Referências bibliográficas}

Amar, G. (2010). Homo mobilis - Le nouvel âge de la mobilité. Éloge de la reliance. Limoges, França: FYP Editions.

Aramayona, B., \& García-Sánchez, R. (2019). Decoding middle-class protest against low-cost nocturnal tourism in Madrid. Journal of Policy Research in Tourism, Leisure and Events, 11(3),1-14. doi: 10.1080/19407963.2019.1584627

Audrey, P. (2017). Mobility. Londres: Routledge.

Baptista, L.V. (2005). Territórios lúdicos (e o que torna lúdico um território): Ensaiando um ponto de partida. Forum Sociológico (13/14), 47-58.

Baptista, L. V. (2016). A dimensão lúdica da cidade: Uma perspectiva de análise a propósito da programação global de lugares para o entretenimento urbano. Em N. M. Augusto (Orgs.), Sociedade em debate (pp. 349-363). Vila Nova de Famalicão: Edições Húmus.

Barata Salgueiro, T., Mendes, L., \& Guimarães, P. (2017). Tourism and urban changes. Lessons from Lisbon. Em M. Gravari-Barbas, \& S. Guinand (Eds.), Tourism and gentrification in contemporary metropolises: International perspectives (pp. 255275). Nova Iorque: Taylor \& Francis.
Bourdieu, P. (1979). La distinction: Critique sociale du jugement. Paris: Minuit.

Brooks, R. (2018). Higher education mobilities: A cross-national European comparison. Geoforum, 93, 87-96.

Brooks, R., \& Waters, J. (2011). Student mobilities, migration and the internationalization of higher education. Nova Iorque: Palgrave Macmillan.

Burns, P. M., \& Novelli, M. (Eds.) (2008). Tourism and mobilities: Local-global connections. Cambridge, MA: CABI

Cicchelli, V. (2012). L'esprit cosmopolite. Voyages de formation juveniles et cultures européennes. Paris: Les Presses de Sciences Po.

Cócola-Gant, A. (2018). Tourism gentrification. In L. Lees, \& M. Phillips (Eds.), Handbook of gentrification studies (pp. 281-292). Cheltenham, RU: Edward Elgar.

Coles, T., \& Hall, C. M. (2008). Editorial: The geography of tourism is dead. Long Live geographies of tourism and mobility. Current Issues in Tourism, 9(4-5), 289-292. doi: 10.1080/13683500608668250

Colomb, C., \& Novy, J. (2017). Protest and resistance in the tourist city. Londres: Routledge.

Davidson, M., \& Lees, L. (2005). New-build "gentrification" and London's riverside renaissance. Environment and planning A, 37(7), 1165-1190.

Firmino da Costa, A. (2008 [1999]). Sociedade de bairro: Dinâmicas sociais da identidade cultural. Oeiras, Portugal: Celta.

Füller, H., \& Michel, B. (2014). "Stop being a tourist!" New dynamics of urban tourism in Berlin-Kreuzberg. International Journal of Urban and Regional Research, 38(4), 1304-1318. doi: 10.1111/14682427.12124

Giddens, A. (1991). Modernity and self-identity: Self and society in the late modern age. Cambridge: Polity.

Hall, C. M. (2008). Tourism planning: Policies, processes and Relationships. Essex, Reino Unido: Pearson.

Hall, C. M. (2015). On the mobility of tourism mobilities. Current Issues in Tourism, 18(1), 7-10.

Hall, C. M., \& Williams, A. (2008). Tourism and innovation. Londres: Routledge.

Hannigan, J. (2010). Urban entertainment destination. Em Ray Hutchison (Ed.), Encyclopedia of urban studies (pp. 868-871). Sage Publications Inc.

Jover, J., \& Díaz-Parra, I. (2019). Gentrification, transnational gentrification and touristification in Seville, Spain. Urban Studies. doi: $10.1177 / 0042098019857585$

Kaufmann, V., Bergman, M., \& Joye, D. (2004). Motility: Mobility as capital. International Journal of Urban and Regional Research, 28(4), 745-756. doi: 10.1111/j.0309-1317.2004.00549.x

King, R. (2017). Theorising new European youth mobilities. Population, Space and Place, 24(1), e2117. doi: $10.1002 /$ psp.2117 
Lynch, P., Molz, J. G., Mcintosh, A., Lugosi, P., \& Lashley, C. (2011). Theorizing hospitality. Hospitality \& Society, 1(1), 3-24. doi: 10.1386/hosp.1.1.3_2

Marinescu, N. (2017). Trends in European tourism: The case of educational tourism inside the Erasmus program. Bulletin of the Transilvania University of Brasov. Economic Sciences. Series V, 10(2), 281-286.

Mavric, M., \& Urry, J. (2009). Tourism studies and the new mobilities paradigm. Em J. Tazal \& M. Robinson (Eds.), The SAGE handbook of tourism studies (pp. 645-657). Nova Iorque: Sage.

Mendes, L. (2018). The Panacea of touristification as a scenario of post-capitalist crisis. In I. David (Ed.), Crisis, austerity, and transformation: How disciplinary neoliberalism is changing Portugal ( $\mathrm{pp}$. 25-46). Londres: Lexington Books.

Merriman, P. (2012). Mobility, space \& culture. Londres: Routledge.

Nofre, J. (2019). O Airbnb, o lazer e a economia da noite. Em J. A. Rio Fernandes (Ed.), O Airbnb em Lisboa (pp. 67-68). Porto: Book Cover Editora.

Nofre, J., Giordano, E., Eldridge, A., Martins, J. C., \& Sequera, J. (2018). Tourism, nightlife and planning: Challenges and opportunities for community liveability in La Barceloneta. Tourism Geographies, 20(3), 377-396. doi: $10.1080 / 14616688.2017 .1375972$

Nofre, J., Sánchez-Fuarros, I., Carlos Martins, J., Pereira, P., Soares, I., Malet-Calvo, D., Geraldes, M., \& López Díaz, A. (2017). Exploring nightlife and urban change in Bairro Alto, Lisbon. City \& Community, 16, 330-344. doi:10.1111/cico.12248

Proença, S., \& Soukiazis, E. (2008). Tourism as an economic growth factor: A case study for Southern European countries. Tourism Economics, 14(4), 791-806. doi: 10.5367/000000008786440175

Scott, A. J. (2006). Creative cities: Conceptual issues and policy questions. Journal of urban affairs, 28(1), 1-17.

Sequera, J., \& Nofre, J. (2018a). Shaken, not stirred: New debates on touristification and the limits of gentrification. City, 5(6), 843-855. doi: 10.1080/13604813.2018.1548819

Sequera, J., \& Nofre, J. (2018b). Urban activism and touristification in Southern Europe: Barcelona, Madrid and Lisbon. Em J. Ibrahim, \& J. Roberts (Eds.), Contemporary left wing activism (Vol. II): Democracy, participation and dissent in a global context (pp. 88-105). Londres: Routledge.

Sequera, J., \& Nofre, J. (2019). Transnational gentrification, touristification and urban change in Alfama. Urban Studies. doi: 10.1177/0042098019883734

Stevens, Q. (2007). The ludic city: Exploring the potential of public spaces. Nova Iorque: Routledge.

Thomas, R., \& Augustyn, M. (Eds.) (2007). Tourism in the new Europe. Londres: Routledge.

Tribe, J. (2011). The Economics of recreation, leisure and tourism. Londres: Routledge.

Young, M., \& Willmott, P. (1986 [1957]). Family and Kinship in East London. Londres: Routledge \& Kegan Paul.

Luís Vicente Baptista. Faculdade de Ciências Sociais e Humanas, Universidade Nova de Lisboa (NOVA FCSH) \& Centro Interdisciplinar de Ciências Sociais (CICS.NOVA). Avenida de Berna, 26-C, 1069-061 Lisboa, Portugal. Email: luisv.baptista@fcsh.unl.pt

Jordi Nofre. Faculdade de Ciências Sociais e Humanas, Universidade Nova de Lisboa (NOVA FCSH) \& Centro Interdisciplinar de Ciências Sociais (CICS.NOVA). Avenida de Berna, 26-C, 1069-061 Lisboa, Portugal. Email: jnofre@fcsh.unl.pt

Maria do Rosário Jorge. Faculdade de Ciências Sociais e Humanas, Universidade Nova de Lisboa (NOVA FCSH) \& Centro Interdisciplinar de Ciências Sociais (CICS.NOVA). Avenida de Berna, 26-C, 1069-061 Lisboa, Portugal. Email: jmrg@fcsh.unl.pt 